\title{
Our debt to those who are dying: the UK medical establishment should reconsider its stance on assisted suicide
}

Just when you thought it had gone away, the debate on assisted suicide is back. Debbie Purdy, who has multiple sclerosis, took her case to the House of Lords to seek assurance that her husband would not be prosecuted for assisting her to commit suicide, and the House of Lords referred it to the Director of Public Prosecutions (DPP). The DPP has now issued an interim statement and invited consultations (the closing date for responses is 16 December 2009). ${ }^{1}$ The judicial decision was at least in part a response to the wholly unsatisfactory position that the authorities in the UK seemed to be condoning acts carried out by UK citizens abroad that would be illegal here.

The medical profession in the UK is in general opposed to legalising assisted dying, and those working in palliative medicine are more opposed than any other group. ${ }^{2}$ The Royal College of General Practitioners debated the subject 4 years ago, and agreed a policy that there should be no change in the existing law. ${ }^{3}$

In this issue of the BJGP, Hussain and White report on a qualitative study of GPs' attitudes. ${ }^{4}$ They found a range of opinions, with some taking the view that involving doctors in euthanasia would always be wrong, and others seeing it as a potentially useful service to patients suffering intolerably. It should not surprise that some quoted their own family experiences as powerful determinants of their attitudes.

The study reports many of the familiar arguments opposing any change: that assisting suicide is not a part of what we do as doctors; we risk damaging our relationships with patients and losing their trust; and a change could discourage efforts to improve palliative care and blunt our respect for human life.

In my view, the medical establishment has got it wrong. It is striking that most of the arguments are not about the principle of assisted suicide, but about the consequences or the practicalities of introducing assisted suicide. One of the doctors in Hussain and White's study is quoted as saying '.. people do have a right to determine how their life goes as much as they can ...'. It would be difficult to argue against the principle.

Contemporary societal attitudes have elevated patient autonomy to the point where it outweighs almost every other ethical principle. Collectively, we no longer believe that suicide is a sin, and it seems entirely acceptable in principle that patients with terminal illness should be able to choose the time and place of their own death. We might feel that there is something peculiarly modern about wanting to die 'with dignity', and that dying should reflect the messiness and unpredictability of life. But our practice of medicine in every other respect seeks to relieve suffering and respect patients' dignity as far as possible. It would be odd to abandon our commitment to patients' autonomy and dignity only when death approaches.

Where some of the other arguments are concerned, our persisting opposition to a change in the law reflects an insular unwillingness to learn from experience elsewhere. Our colleagues in the Netherlands have assured us that their commitment to palliative care has not been impaired by the existence of assisted suicide. One report reviewed medical practice at the end of life in a 5-year period following a change in reporting practice. It found a predicted increase in reported euthanasia, but concluded that physicians were not moving down a slippery slope, nor that decision making had become less careful. The authors found that the number of requests for euthanasia had increased, but that most requests were not granted. ${ }^{5}$

A more recent study from Belgium concluded that decisions to shorten life were not related to lower use of palliative care, and discussions often took place as part of multidisciplinary palliative care. ${ }^{6}$ Many of us are concerned that vulnerable older people will feel obliged to agree to euthanasia in order to avoid becoming a burden, or in response to less subtle pressures. This looms so large in many doctors' moral reasoning that it seems to outweigh considerations of dignity and autonomy, as if we were fearful of our ability to protect patients from coercion. However, here too the argument seems inadequate. It ignores both the experience of doctors in other countries dealing with assisted suicide, and our own experience here of protecting patients from undue influence in other settings.

There are further anomalies in the interim policy. Family members are specified as one group who are likely to avoid prosecution if they feel they are responding compassionately to someone with a terminal illness, severe physical disability, or a severe degenerative physical condition. However, the document says early on, rather disarmingly, that:

'It may sometimes be the case that the only source of information about the circumstances of the suicide and the state of mind of the victim is the suspect.' (paragraph 17)'.

Quite so. The safeguards against coercion look pretty flimsy.

If doctors feel that vulnerable older people need protection, then we should be campaigning vigorously for a change in the law, and try to engage the public in a debate about the nature and extent of the safeguards required. It is perhaps a paradox that such safeguards may come as part of a new law to allow euthanasia. GPs are as well placed as any other group to speak up for the protection of our patients, and maintaining our current dignified silence is not going to help anyone. We remain an important presence in palliative care $^{7}$ and we have a strong 
vested interest in ensuring that any change does not compromise core values.

However, there are other arguments for changing our collective stance. There seems to be a collective, if unspoken, belief that if we oppose any change strongly enough our view will prevail. It amounts to an atavistic 'doctor knows best' attitude that few among us would bring into our consulting rooms. It makes us look paternalistic, as if we have learned nothing in the last 50 years about the need to consult and involve patients.

The public understands these issues perfectly well, and it's not clear that the fundamental decision is one that we should be involved in at all. We can share our concerns, and comment on the kind of safeguards that need to be put in place, but if the public wants to see such a change enacted then it is up to the public, and not us, to make that decision. We need to remember that we are ultimately not the public's masters, but its servants.

\section{David Jewell}

Editor, BJGP

\section{Provenance}

Freely submitted; not peer reviewed

\section{Acknowledgements}

Thanks to George Freeman and David Kessler for comments on an earlier draft. The views are those of the author only, and not supported by the Royal College of General Practitioners.

\section{REFERENCES}

1. The Crown Prosecution Service. Interim policy for prosecutors in respect of cases of assisted suicide. http://www.cps.gov.uk/consultations/as_policy.html (accessed 7 Oct 2009).

2. Seale C. Legalisation of euthanasia or physicianassisted suicide: survey of doctors' attitudes. Palliat Med 2009; 23(3): 205-212.

3. Royal College of General Practitioners. RCGP statement on assisted dying. London: RCGP, 2005. http://www.rcgp.org.uk/default.aspx?page $=1544$ (accessed 7 Oct 2009).

4. Hussain T, White P. GPs' views on the practice of physician-assisted suicide and their role in proposed UK legalisation: a qualitative study. Br J Gen Pract 2009; 59(568): 844-849.

5. Van der Maas PJ, Van der Waal G, Haverkate I, et al. Euthanasia, physician-assisted suicide, and other medical practices involving the end of life in the Netherlands 1990-1995. N Engl J Med 1996; 335(22): 1699-1705.

6. Van den Block L, Deschepper R, Bilsen J, et al. Euthanasia and other end of life decisions and care provided in final three months of life: nationwide retrospective study in Belgium. BMJ 2009; 339: b2772.
7. Neergaard MA, Vedsted P, Olesen F, et al. Associations between home death and GP involvement in palliative cancer care. Br J Gen Pract 2009; 59(566): 671-677.

DOI: 10.3399/bjgp09X472863
David Jewell

BJGP, Editorial Office,

14 Princes Gate, London SW7 1PU.

E-mail: David.Jewell@bristol.ac.uk 